\title{
HYBRID MICRO GRID MAXIMUM POWER CONDITION CONTAINING PV/ VARIABLE SPEED WIND GENERATION
}

\author{
M.M.A. Mahfouz \\ Faculty of Engineering, Helwan, Helwan University \\ E-Mail:mohamed.mahfouz@yahoo.co.uk
}

\begin{abstract}
Distribution systems with distributed energy resources, such as photo voltaic power systems (PV) and wind turbines form the new planned micro grids (MGs). From the customer point of view, MGs improve power quality by supporting voltage levels and potentially lower costs of energy supply. Despite the obvious advantages of distributed generation, technical challenges associated with the operation and controls of MGs are immense in order to provide stable frequency and voltage in the presence of variable loading and emergency condition. This paper proposes an efficient an overhaul maximum power conditioning control system of micro grid feeds from PV array and wind turbine. The PV power conditioning system utilizes two-stages energy conversion system topology composed of a DC/DC boost converter and voltage source inverter (VSI) that satisfies the MG technical requirements. For the proposed PV maximum power point tracking (MPPT), the boost converter duty cycle is being adjusted to set the operating point of the PV panel at the maximum power point. While for the proposed wind turbine the pitch angle is controlled to allow the wind turbine operates at its optimum condition at low and medium wind speeds, while at high wind speeds region, the pitch angle is being increased to shed some of the aerodynamic power. The dynamic modeling and control of the studied MG are presented for steady state and transient operation conditions. Moreover, the control strategies to obtain the maximum converted power and stabilize the voltage under different operating conditions are derived in the submitted paper.

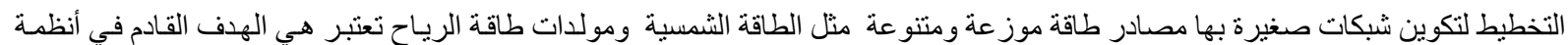

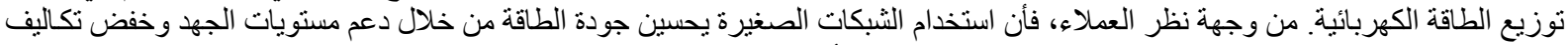

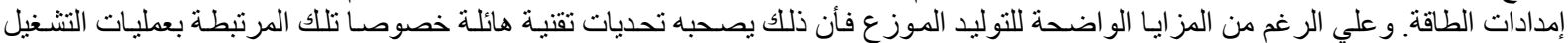

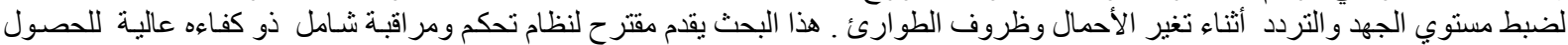

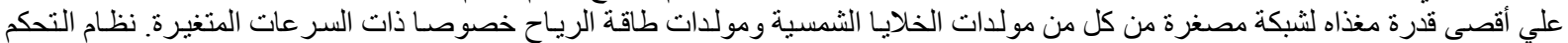

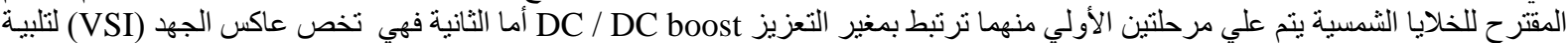

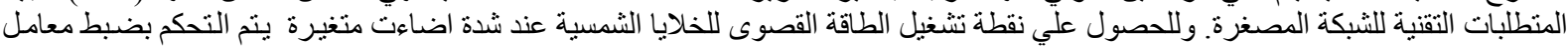

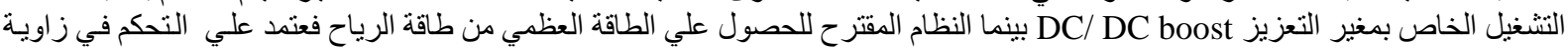

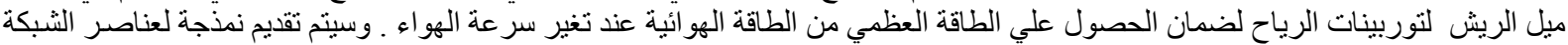

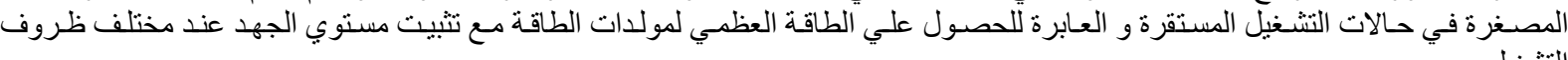

Keywords: Micro Grid, Photovoltaic (PV) array, Wind energy, DC/DC boost converter, Voltage source inverter, Pitch control.

\section{INTRODUCTION}

Distributed generation (DG) is one of the fastest growing areas of research in today's evolving power systems. Although the concept of generating power from multiple dispersed locations is not new, the introduction of renewable energy sources and small capacity fossil fuel generators to the centralized power system grid is a relatively new concept [1]. Several reasons have caused the shift towards a more decentralized power system. Electricity market deregulation and the increased environmental concerns regarding greenhouse gases are considered two of the main reasons behind that change [2]. Interconnection of different DG units to distribution network forms a new system called micro-grid. Micro-grids with DG close to load centers will reduce the required power flows from transmission and distribution networks resulting in loss reduction and reliability increase. Micro grids can enhance system performance by relieving the overloading of the network and aiding the operating engineer to speed up the restoration process after blackouts due to fault or emergency conditions [3]. Distributed

Engineering Research Journal, Vol. 37, No.1, January 2014, PP: 13-20 
generations used in micro grids are technically not suitable for direct energy supply to the grid. They have to be interfaced with Micro Grid through an inverter in order to provide the required voltage and frequency under time varying load. Ensuring stable MG's operation during network disturbances, maintaining stability and power quality requires the development of sophisticated design and control strategies for the interfaced converters [4-5]. Photovoltaic arrays PV are one of the DG sources that have been growing steadily in the last few years. This is primarily due to its increasing power conversion efficiency and the decreasing costs of installing new PV systems. In order to capture the maximum power for the PV array, a maximum power point tracker (MPPT) is required. This point of solar panels is a function of solar radiations and temperature and this function can be implemented either in the dc-dc converter or in the dc-ac converter. Several algorithms can be used in order $t$ to implement the MPPT such as; Perturb and Observe, Incremental Conductance, Parasitic Capacitance and Constant Voltage [6].Wind turbines are designed to produce electrical energy as cheaply as possible, therefore generally they are designed so that they yield maximum output at its nominal wind speeds. In case of stronger winds it is necessary to waste part of the excess wind energy to avoid damaging the wind turbine. All wind turbines are therefore designed with some sort of power control, there are different ways of doing this safely on modern wind turbines; one of these is the pitch control. During a pitch controlled wind turbine the power output is being checked several times per second, if the power output becomes too high, it sends an order to the blade pitch mechanism which immediately turns the rotor blades slightly out of the wind. Conversely, the blades are turned back into the wind whenever the wind drops again. The rotor blades thus have to be able to turn around their longitudinal axis to pitch. During normal operation the blades will pitch a fraction of a degree at a time and the rotor will be turning at the same time [7]. Designing a pitch controlled wind turbine requires experience in order to keep the rotor blades at the optimum angle to maximize output for all speeds. ents data is shown in the Appendix.
This paper, studies the steady state and transient behavior of micro grid under varying climate conditions and three phase fault .To assess the system behavior a complete model will be developed to simulate the MG's components including power conditioning system. Maximum power tracked for PV array using the constant voltage (CV) algorithm. Also pitch control for wind turbine under time varying of wind speed and solar radiation will be introduced. To conduct the proposed studies, the layout of the studied MG is presented in Section 2. Section 3 gives solar and wind energy driven DG units modeling and presents the description of the proposed overhaul control technique to have the maximum power conditioning. While the studied cases with results and discussions are explained in Section 4 and finally the conclusions are presented in Section 5 .

\section{MICROGRID COMPONENTS MODELING}

Micro grid system under study single line diagram is illustrated in Fig. 1. It consists of $22 \mathrm{kV}$ interconnected network with $200 \mathrm{~kW}$ PV panel and $660 \mathrm{~kW}$ variable speed wind turbine. Both of WT and PV are connected to the grid and each others with three short transmission lines with length of 20 $\mathrm{Km}$. The studied PV array is poly crystalline silicon and consists of 36 cells per module with an open circuit 20.8V, 33 series modules and 119 parallel modules PV bus has a local load of 120 active power $\mathrm{kW}$ and reactive power of $50 \mathrm{kVAR}$ while the wind local bus load is $280 \mathrm{~kW}$ and $100 \mathrm{kVAR}$. The PV arrays are connected to the grid through DC/DC boost converter and DC/AC three-phase two-level inverter. After inversion the arrays are interfaced to the DG through a transformer $6 \mathrm{kV} / 22 \mathrm{kV} 250 \mathrm{kVA}$, while, the WT is connected to MG through $800 \mathrm{kVA}$, $690 \mathrm{~V} / 22 \mathrm{kV}$ transformers. The turbine rated wind speed is $12 \mathrm{~m} / \mathrm{s}$ with pitch control and it is coupled to self excited induction generator (SEIG). In the case of SEIG with fixed capacitor, the system may need additional source of reactive power from the grid to enhance system performance. The DG voltage variations are recorded due to wind speed and radiation fluctuations. The complete micro grid elem 
M.M.A. Mahfouz " Hybrid micro grid maximum power condition ...."

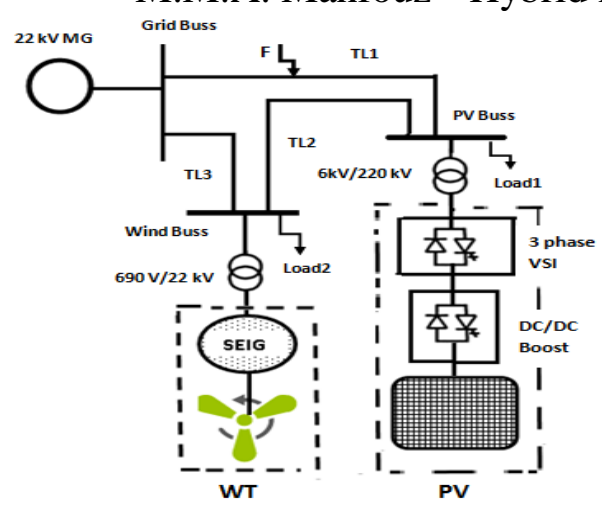

Fig.1: Studied micro grid single line diagram

\section{PROPOSED MAXIMUM POWER OVERHAUL SCHEME}

The proposed overhaul control scheme target is to have maximum power conditions for both PV array and the wind turbine. For PV array, MPPT constant voltage is applied for the boost converter and the three phase two level PWM inverter. While for wind turbine pitch control being used. In this section the detailed descriptions for both algorithms are introduced.

\subsection{PV Array MPPT}

The equivalent circuit model of a PV cell is needed to simulate its real behavior using the physics of $p-n$ junctions, a cell can be modeled as a DC current source in parallel with diode that represents the most effective current escaping due to diffusion and charge recombination mechanisms. Two resistances, $R_{s}$ and $R_{p}$ are included to $m$ represent the contact resistances and the internal PV cell resistance respectively. These two resistance values are usually obtained from measurements or applying the curve fitting technique based on the cell I-V characteristic. The current source $I_{p h}$ represents the photo cell current. The relationships between the PV cell output current and terminal voltage is given by [8]:

$I=I_{p h}-I_{r s}\left[\exp \left(\frac{\mathrm{q}\left(\mathrm{V}+\mathrm{IR}_{s}\right)}{\mathrm{AKT}}\right)-1\right]-\frac{V+I R_{s}}{R_{p}}$

Where; $A$ is the diode ideality factor, $k$ is the Boltzmann constant $\left(1.3806503 \times 10^{-23} \mathrm{~J} / \mathrm{K}\right), T$ is the cell temperature in Kelvin, $q$ is the electron charge $\left(1.60217646 \times 10^{-19} \mathrm{C}\right), I_{r s}$ is the reverse saturation currents of the diode, respectively. PV cells are grouped in larger units called PV modules, which are further interconnected in a parallel-series configuration to form PV arrays or PV generators. Assuming high value of $\mathrm{R}_{\mathrm{p}}$ then for an array with $N_{s}$ series and $N_{p}$ parallel-connected cells, the array current may be related to the array voltage as:
$I=N_{p}\left[I_{p h}-I_{r s}\left(\exp \left(\frac{q\left(V+I R_{s}\right)}{A K T N_{s}}\right)-1\right)\right]$

Where: $I_{r s=} I_{r r}\left(\frac{T}{T_{r}}\right)^{3} \exp \left[\frac{\mathrm{E}_{\mathrm{G}}}{\mathrm{AK}}\left(\frac{1}{\mathrm{~T}_{\mathrm{r}}}-\frac{1}{\mathrm{~T}}\right)\right]$

Where; $I_{r s}$ is the cell reverse saturation current at temperature $\mathrm{T}$, while $T_{r}$ is the cell reference temperature, $I_{r r}$ is the reverse saturation current at $T_{r}$ and $E_{G}$ is the band gap energy of the semiconductor used in the cell. The photocurrent $I_{p h}$ depends on the cell's temperature and radiation as follows:

$I_{p h=}\left[I_{S C R}+k_{i}\left(T-T_{r}\right)\right] \frac{s}{100}$

Where; $I_{S C R}$ is the cell short circuit current at reference temperature and radiation, $k_{i}$ is the short circuit current temperature coefficient and $S$ is the solar radiation in $\mathrm{mW} / \mathrm{cm}^{2}$. A grid-connected $\mathrm{PV}$ solar system is to transfer the maximum power obtained from the PV panel into the MG independently of the climatic conditions. Therefore, the use of an appropriate electronic interface with maximum power point tracking (MPPT) capabilities is required. The output power of the PV cell has a nonlinear function with irradiance and temperature. Therefore, the power of the PV array changes continuously and consequently the PV operating point must change to maximize the energy produced. To achieve this target, a control algorithm to have MPPT operation for both the boost and PWM inverter is proposed and its block diagram is shown in Fig.2. The constant voltage (CV) algorithm is applied due to its simplicity for MPPT control method. It illustrated that, the PV array operating point is kept near the MPP by regulating the voltage to match it to a fixed reference voltage $V_{\text {ref. }}$. The $V_{\text {ref }}$ value is set equal to the $\mathrm{V}_{\mathrm{MPP}}$ of the PV module. This method assumes that individual insulation and temperature variations on the array are insignificant, and that the constant reference voltage is an adequate approximation of the true MPP. This means that CV algorithm is based on approximately constant ratio between $\mathrm{V}_{\mathrm{MPP}}$ and $\mathrm{V}_{\mathrm{oc}}$ as given in eqn. (5):

$\mathrm{V}_{\mathrm{MPP}} \cong \mathrm{kV}_{\text {oc }}$

By the adjusting of array voltage to this calculated value, the operation at MPP is achieved. The measurement of the voltage $\mathrm{V}_{\mathrm{PV}}$ is necessary in order to set up the duty-cycle of the DC/DC converter.

\subsubsection{Booster control}

A boost converter is a power converter with an output DC voltage greater than its input DC voltage. By implementing the PWM technique on boost converter, a stable output voltage from a non-stable 
M.M.A. Mahfouz " Hybrid micro grid maximum power condition ...."

input voltage can be obtained by changing the duty cycle (d) of the switched input pulse. The boost converter with a switching period (Ts), the $\frac{V_{0}}{V_{i}}=\frac{T_{s}}{t_{\text {off }}}=\frac{1}{1-d}$

After determining the value for $\mathrm{V}_{\mathrm{MPP}}$, the DC/DC boost converter is switched to quickly force the array terminal voltage to its MPP. As illustrated in Fig. (2), the difference between MPP fraction voltage and the array output represents the error of the PI controller. This PI controller regulates the PV array voltage by continuously switching on and off of the IGBTs at high frequency according to the varying duty cycle. The fast switching action of the boost converter decouples the dynamics of the PV array due its changes in voltage or current from that of the DC link capacitor, which offers good performance under changing weather conditions. The other advantage of using the boost converter is to increase the array voltage to higher levels suitable for grid interconnection.

\subsubsection{VSI three phase PWM inverter control}

Among various modulation techniques for MMI, PWM is an attractive candidate due to efficient DC link voltage utilization, reducing commutation losses and total harmonic distortion THD. The proposed inverter is a three-phase, two-level DC/AC inverter using IGBTs due to their lower switching losses. Depending on the gating signals, the output terminal voltage is either equal to capacitor voltage or zero, and can be expressed by [10]:

$V_{i n v}=N * V_{\text {cap }}$

Where; $V_{i n v}, N$, and $V_{c a p}$ are terminal voltage, gating signal and capacitor voltage, respectively. $N$ takes the value of either one or zero. In the two-level inverter the switching of the upper and lower IGBT generates the output voltages with positive and negative levels $(+\mathrm{Vdc}$ and $-\mathrm{Vdc})$. The inverter is generally connected to the network at the PCC through the equivalent inductance and resistance, which represent the impedance of the coupling transformer. The magnetizing inductance of the stepup transformer can also be taken into consideration through a mutual equivalent inductance. The aim of the control strategy is to regulate the current output from the inverter to follow a specified reference value. This can be achieved by transforming the three phase output currents of the inverter to the rotating reference frame $(\mathrm{dq} 0)$. The relation between the DC side voltage $V_{d c}$ and the generated $\mathrm{AC}$ voltage $\mathrm{V}_{i n v}$ can be described through the matrix in the $d q$-frame $\mathrm{S}_{\mathrm{av}}, d q$, as given by: relationship between output $\mathrm{V}_{0}$ and $\mathrm{V}_{\text {in }}$ voltage is governed by [9];

$\left[\begin{array}{c}V_{i n v, d} \\ V_{i n v, q}\end{array}\right]=S_{a v, d q} V_{d c}$

Where; $S_{a v, d q}=0.866 m_{i}$

And $\mathrm{m}_{\mathrm{i}}$ is the inverter modulation index. A phase locked loop was used to lock on the grid frequency in such a way that $\mathrm{V}_{\mathrm{q}}$ was set to zero [8]. If the grid voltage is relatively constant, $\mathrm{I}_{d}$ and $\mathrm{I}_{\mathrm{q}}$ can be used to control real and reactive power injections from the PV array. In order to inject real power from the inverter, $I_{d}$ was controlled using PI controller to follow a specified reference signal $\mathrm{I}_{\mathrm{d} \_\mathrm{REF}}$, reactive power injection was set to zero and thus $I_{q}=0$, as displayed in Fig.2. The $I_{d_{-} R E F}$ was extracted from the DC link capacitor. A constant DC voltage across the capacitor means that the power that goes into it from the PV array matches the power going out to the inverter [11]. As previously mentioned, the input power $\mathrm{P}_{\text {in }}$ to the capacitor was controlled to be the MPP of the PV array output power by the DC-DC converter. The PI controller was used to extract $\mathrm{I}_{\mathrm{d} \text { REF }}$ from the error mismatch between Pin and Pout according to the following relation:

$I_{d_{-} R E F}=\frac{1}{V_{d}}\left(K_{p}\left(P_{\text {in }}-P_{\text {out }}\right)+K_{I} \int\left(P_{\text {in }}-P_{\text {out }}\right) d t\right)$

Where $K_{P}$ and $K_{I}$ are the proportional and integral controller constant, respectively and $\mathrm{V}_{\mathrm{d}}$ is the direct component of the voltage at PCC. The output of the PI-Controller is Modulation index $\mathrm{m}$, which is fed to PWM switching circuit.

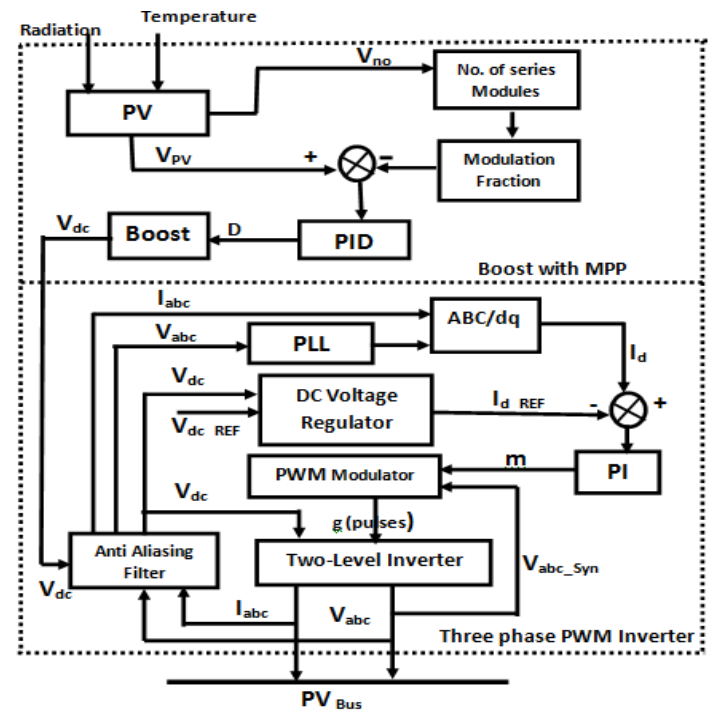

Fig. 2: PV grid connected control block diagram 


\section{M.M.A. Mahfouz " Hybrid micro gri 3.2 Wind Turbine Pitch Control}

The variable speed wind turbine extracted power depends on some main factors such as available wind power, the power curve of the machine and the ability of the machine's response to wind fluctuation which is mainly depend on the used control algorithm. The mechanical power produced by the wind is given by:

$p_{w}=0.5 \rho \cdot A \cdot C_{p}(\lambda, \beta) \cdot V_{w}{ }^{3}$

Where; $P_{w}$ is the aerodynamic power, $C p(\lambda, \beta)$ is the dimensionless aerodynamic power performance coefficient, $\rho=1.25 \mathrm{~kg} / \mathrm{m} 3$ is the air density, $A\left(\mathrm{~m}^{3}\right)$ is the rotor swept area, $V_{w}$ is the wind speed $(\mathrm{m} / \mathrm{sec}), \lambda$ is the tip-speed ratio and $\beta$ represents pitch angle.

The tip speed ratio is defined as:

$\lambda=\varpi_{m} \frac{R}{V_{w}}$

Where; $\omega_{\mathrm{m}}$ is the rotor speed $(\mathrm{rad} / \mathrm{sec})$ and $\mathrm{R}$ is the rotor radius. The wind turbine can be characterized by its $\left(C_{P}-\lambda\right)$.It is seen that if the rotor speed is kept constant, then any change in the wind speed will change the tip-speed ratio, leading to the change of power coefficient $C_{p}$ as well as the generated power. If, however, the rotor speed is adjusted according to the wind speed variation, then the tip-speed ratio can be maintained at an optimal point, which could yield maximum power output from the system. For the modeling of the wind turbine the power coefficient $\mathrm{Cp}(\lambda, \beta)$ of eqn. (13) is used, which represents the fraction of the power in the wind captured by the turbine a It is assumed that the wind turbine is operated at high $C_{P}$ values most of the time to have the target maximum power.

$C_{p}=0.5\left(\lambda-0.022 \beta^{2}-5.6\right) e^{-0.17 \lambda}$

$p_{T}=0.5 \rho \cdot A \cdot C_{p T}\left(\frac{R}{\lambda_{T}}\right)^{3} \varpi_{m}^{3}$

$p_{T}=K_{P}(R P M)^{3}$

Where; $\mathrm{P}_{\mathrm{T}}$ is the target power at max. $\mathrm{C}_{\mathrm{p}}$;

$\mathrm{C}_{\mathrm{p} \mathrm{T}}=\mathrm{C}_{\mathrm{p}}\left(\lambda_{\mathrm{T}}\right)$

$\mathrm{K}_{P}$ is the computed wind turbine data and RPM is the rotor speed. For a fixed-frequency application such our case of study, the induction generator rotor speed varies by a few percent; based on the slip; above the synchronous speed while the wind speed may vary across a wide range. The pitch control system is one of the most widely used control techniques to regulate the output power of a wind turbine generator. It relies on the variation in the power id maximum power condition ...."

captured by the turbine as the pitch angle of the blades is changed. It is generally used for speed control, power production optimization and to start /stop the turbine. This paper target is that, the wind turbine should be operated at maximum $C_{P}$ most of the time. During lower wind speed region, the aerodynamic power produced by the wind turbine is below the maximum power rating of the wind, to achieve this objective; the pitch angle of the wind turbine is regulated to obtain the maximum possible $\mathrm{C}_{\text {Pmax }}$. As the rpm changes according to wind speed, the pitch angle is changed to keep its optimum power. To fulfill this study aim a proposed applied pitch control algorithm is shown in Figure 3 using PID pitch controller which generates the pitch angle required for capturing the maximum wind power. The PID uses the error between the desired maximum mechanical output power $\mathrm{P}_{\mathrm{m}-\mathrm{REF}}$ equal to (1pu) and actual captured mechanical power $\left(\mathrm{P}_{\mathrm{m}}\right)$, which resulting from the variable wind velocity to determine the required pitch angle. The desired pitch angle output is connected to a limiter to make sure that the pitch angle value is within the permissible range and by setting the limiter $\left(b_{\max }\right)$. The PID gains for system controller are designed off line using the Zeigler-Nicholas rules for tuning their parameters.

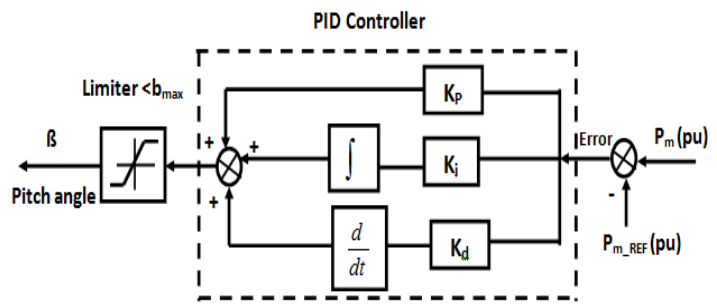

Fig. 3: Wind turbine pitch control block diagram.

\section{SIMULATION RESULTS}

For the studied micro grid system illustrated in Fig.1, the micro-grid sources considered comprise of a photovoltaic generator equipped with constant voltage Maximum Power Point Tracker (MPPT) and a variable speed wind turbine equipped with maximum power pitch controller. The system has been tested under different normal and abnormal operation conditions. As sample of input weather data, the variations in wind speed and solar radiation are displayed in Fig. 4. Three phase faults was been applied on the midpoints of the feeders connecting the grid with the two PCC of the wind farm and PV array. Due to both feeders are short lines the behavior of the system almost the same in both faulty cases moreover the lack of space selected simulation results are displayed to summarize the dynamic 
M.M.A. Mahfouz " Hybrid micro grid maximum power condition ...."

response of the system parameters for only the case of three-phase fault on the feeder connecting the grid with the PCC of the wind bus. This fault is initiated at $2 \mathrm{sec}$. for $100 \mathrm{msec}$. In Figure 5; the dynamic response of the grid bus voltage, current, active and reactive power is depicted. Simulations results show the case of only active power exchange with the grid. During the fault condition the current and power supplied by the grid are rapidly increased and return back to its normal value after fault clearing.

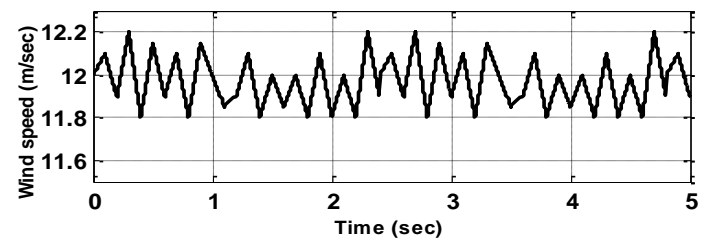

(a)

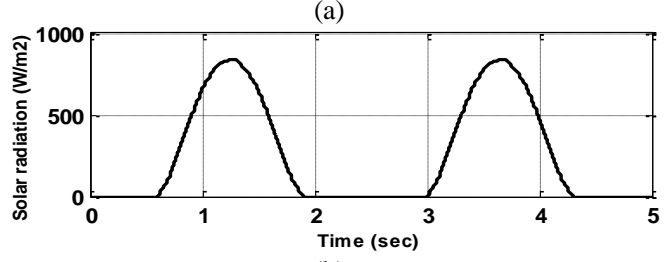

(b)

Fig.4: PV input weather data (a) wind speed (b) solar radiation

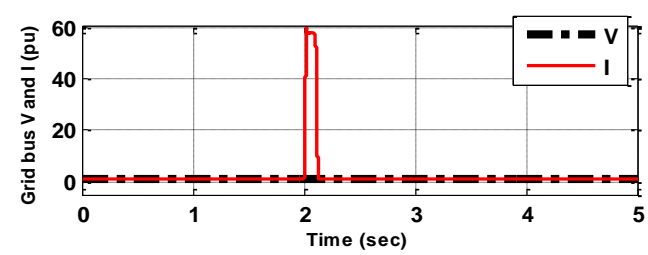

(a)

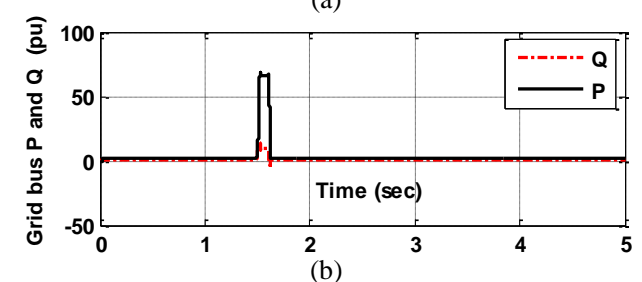

Fig. 5 Grid bus variables (a) Voltage and current (b) active and reactive power

The wind speed is varying as in Fig. (4.a); while the corresponding wind -bus parameters, voltage, current, active, reactive power injected at wind-PCC. Pitch angle, electric torque and the rotor speed are shown in figure (6). During the fault, the voltage magnitude at wind-PCC is dropped suddenly and the injected wind power is consequently decreased as shown in Fig (6.a) and b respectively. While is Fig (6.c), the pitch controller regulate the pitch angle to follow the $\mathrm{C}_{\mathrm{Pmax}}$ operating mode based on the fact that the electric power is controlled to be the cube function of the rotor rpm. The pitch angle control succeeded to keep the rotor speed constant to avoid any acceleration for the generator rotor as introduce in Fig.6.d and the corresponding electric torque is shown in Fig (6.e). The operation will be reset again to $\mathrm{C}_{\mathrm{Pmax}}$ operating mode after fault clearing. This is accomplished due to the fact that the pitch mechanism is capable and efficient for controlling the wind captured power to its maximum value very fast and also keeps the rotor speed constant increasing the rotor stability.

The solar radiation is forced to vary according to day and as described in Fig. (4.b) and the corresponding PV array generated power is shown in Fig. (7.a) Comparing the PV array power with the available solar radiation indicated that the PV generated power matches the solar radiation. The true maximum power point operation for each solar radiation condition is given by the actual produced power, which is rapidly tracked by the proposed simple constant voltage algorithm. Similarly Figure (7.b) shows the variations of the voltage and current at PV-PCC to the distribution feeder. The voltage at the PV-PCC is maintained almost invariant except during the fault it is reduced to $0.8 \mathrm{pu}$. The current response is the same as at the wind-PCC. It is also verified that a very low transient is recorded in the exchanged power of the grid-connected PV system due to the proposed full decoupled current control strategy in $d-q$ coordinates.

To achieve the MPPT constant voltage proposed control algorithm explained before for the PV array, the Boost and Inverter performance variables are shown in Fig.8 demonstrating the Boost duty (D), DC link voltage, three phase inverter PWM modulation index and Inverter phase voltage during the three phase fault at midpoint of the wind-grid feeder. Similar system behavior is obtained for the second study case with the fault at $5 \mathrm{~km}$ from PVPCC. This can be attributed to the short feeder lengths in micro-grids.

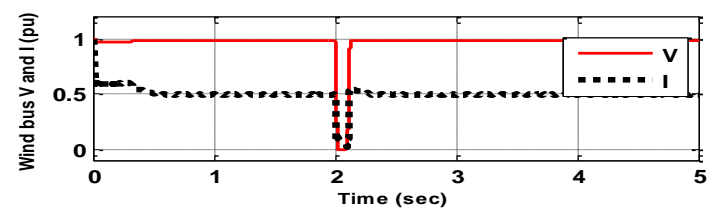

(a)

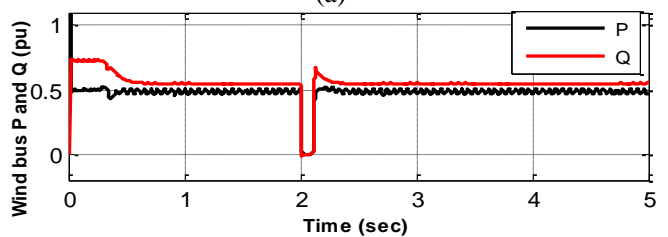


M.M.A. Mahfouz " Hybrid micro grid maximum power condition ...."

(b)

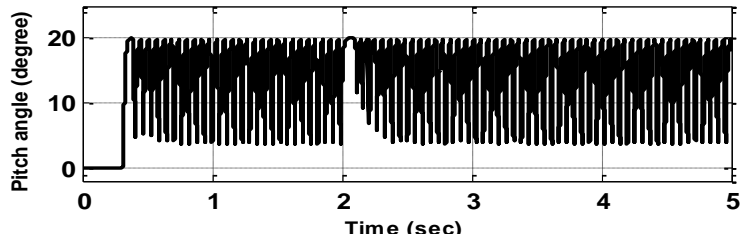

(c)

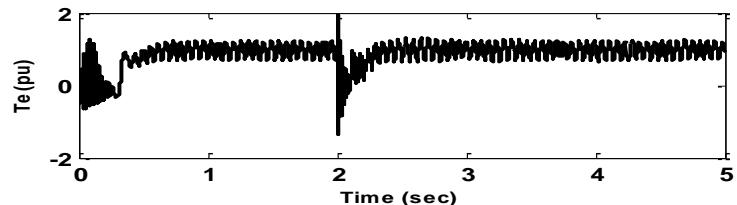

(d)

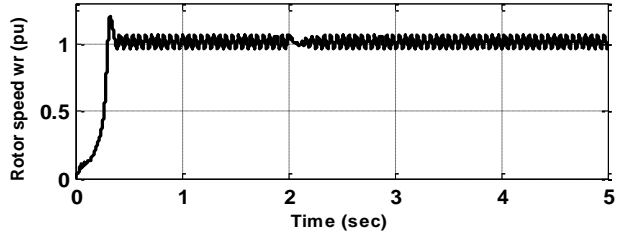

(e)

Fig.6: Wind-PCC (a) voltage and current $(b)$ active and reactive power, $(c)$ pitch angle, $(d)$ electrical torque and (e) rotor speed.

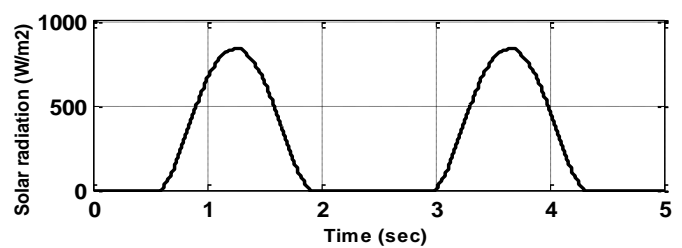

(a)

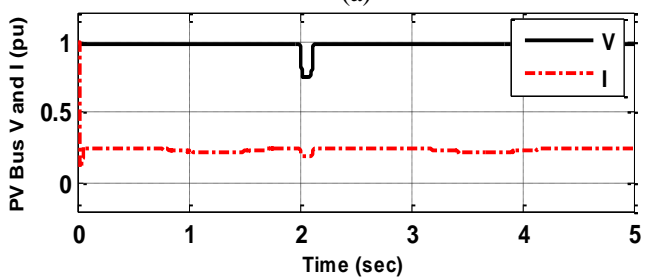

(b)

Fig. 7: PV bus (a) PV array active power (b) voltage and current

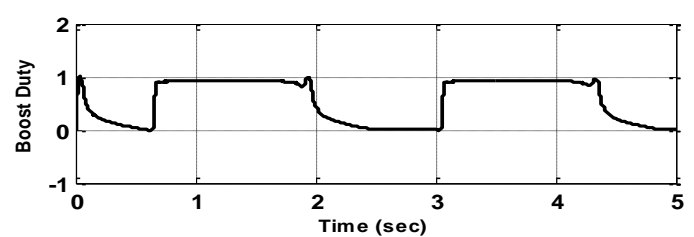

(a)

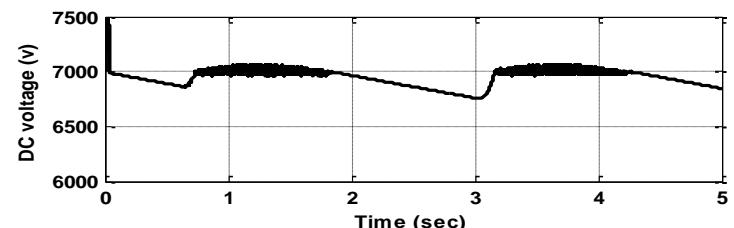

(b)

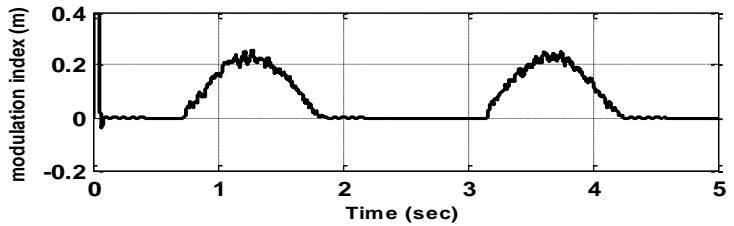

(c)

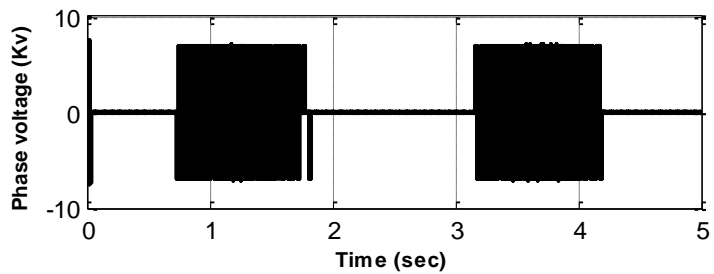

(d)

Fig 8: Boost and Inverter variables (a) Boost duty, (b) Dc voltage Volt. (c) Modulation index and (d) 3phase PWM phase voltage

\section{CONCLUSIONS}

The paper presents a maximum power condition scheme for PV array and wind energy as renewable energy resources integration to micro-grid. Pitch control using PID was applied for wind turbine to regulate the wind generated electrical power around its maximum power at any wind speed. Thereby, the upper limit of captured power is the wind turbine rating. While PV array was integrated through boost converter, three-phase inverter as two stage power conditioning system to enhance the system interface under varying operating or faulty conditions. MPPT constant voltage control is proposed using PI controller, giving direct duty cycle to the boost converter. Simulation results demonstrate the effectiveness of the proposed control approaches and the detailed models presented under short circuit fault condition and solar radiation as well as wind speed variations. The PI and PID controllers were tuned to improve the dynamic behavior of the system, fast recover of reactive power and increase the ability to withstand severe disturbances. The obtained results indicated that the proposed overhaul control scheme maintains voltage and power close to 
M.M.A. Mahfouz " Hybrid micro grid maximum power condition ...."

their nominal values for varying wind speeds and different radiation conditions.

\section{REFERENCES}

[1] G. Pepermans, J. Driesen, D. Haeseldonekx, R. Belmans, and W. D'Haeseleer," Distributed Generation: Definition, Benefits and Issues", Energy Policy 33, PP. 787-798, 2005.

[2]Wang Shouxiang, Wang Hui, Cai Shengxia, "A Review of Optimization Allocation of Distributed Generations Embedded in Power Grid", Automation of Electric Power Systems, 2009 (18).

[3] Wang Chengshan, Wang Shouxiang, "Study on Some Key Problems Related to Distributed Generation Systems", Automation of Electric Power Systems, 2008(20).

[4] J. A. P. Lopes, C. L. Moreira, A. G. Madureira, "Defining Control Strategies for Micro Grids Islanded Operation," IEEE Transactions on Power System, Vol. 21, No. 2, PP. 916-924, 2006.

[5] A. Yazdani, P.P. Dash, "A Control Methodology and Characterization of Dynamics for a Photovoltaic (PV) System Interfaced With a Distribution Network," Power Delivery, IEEE Transactions on, Vol.24, No.3, PP.1538-1551, July 2009.

[6] Wei LI, Luc, Jean -Andre Gregoire Bélanger,“ Control and Performance of a Modular Multilevel Converter System", CIGRÉ Canada, Conference on Power Systems Halifax, September 6- 8, 2011.

[7] Jamal A. Baroudi, Venkata Dinavahi, and Andrew M. Knight" A Review of Power Converter Topologies for Wind Generators", El Sevier Renewable Energy Journal Vol.32,PP2369-2385, 2007.

[8] Ahmed S. Khalifa, Ihab F. El-Saadany, "Control of three phase grid connected Photovoltaic array with open loop maximum power point tracking" IEEE PES General Meeting, July 26-29, 2011 Detroit, MI, USA.

[9] J. Selvaraj, N.A. Rahim, , "Multilevel Inverter For Grid-Connected PV System Employing Digital PI Controller," Industrial Electronics, IEEE Transactions on , vol.56, no.1, pp.149-158, Jan. 2009.

[10] W. Libo, Z. Zhengming, and L. Jianzheng, "A Single-Stage three-Phase Grid-Connected Photovoltaic System With Modified MPPT Method And Reactive Power Compensation", IEEE Transactions on Energy Conversion, vol. 22, no. 4, pp. 881-886, 2007.

[11] H. Patel, V. Agarwal, "MPPT Scheme For A PV-Fed Single-Phase Single-Stage Grid-Connected Inverter Operating In CCM With Only One Current
Sensor", Energy Conversion, IEEE Transactions on , Vol.24, no.1, PP.256-263, March 2009.

[12] Y. Guo, S.H. Hosseini, J.N. Jiang, C.Y.Tang, R.G. Ramakumar, Voltage/Pitch Control For Maximisation And Regulation Of Active/Reactive Powers In Wind Turbines With Uncertainties", IET, Renewable Power Generation, Vol. 6, Issue 2, PP. 99 $-109,2012$.

\section{APPENDIX}

\begin{tabular}{|l|l|}
\hline Poly crystalline silicon PV data: \\
\hline PV Arrav total max. Power & $200 \mathrm{kw}$ \\
\hline Open circuit voltage & $20.8 \mathrm{~V}$ \\
\hline Short circuit current & $3.6 \mathrm{~A}$ \\
\hline No of cells per module & 36 \\
\hline No. of series modules & 33 \\
\hline No. of parallel modules & 119 \\
\hline Open circuit volt. Temp. & $-75 \mathrm{e}-3$ \\
\hline Short circuit current temp. & $75 \mathrm{e}-3$ \\
\hline Temperature & $25 \mathrm{Degree}$ \\
\hline Cell Series resistance & $0.231 \mathrm{Ohm}$ \\
\hline Cell parallel resistance & $3821.772 \mathrm{Ohm}$ \\
\hline Wind Turbine Data: & \\
\hline Power & $660 \mathrm{Kw}$ \\
\hline No. of blades & 3 \\
\hline blades diameter & $47 \mathrm{~m}$ \\
\hline Rated wind speed & $12 \mathrm{~m} / \mathrm{sec}$ \\
\hline Gear ratio & 52.6514 \\
\hline Micro grid and Generator Data: \\
\hline Rated power/Voltage & $660 \mathrm{KW} / 690 \mathrm{~V}$ \\
\hline Rated frequency & $50 \mathrm{~Hz}$ \\
\hline Stator resistance/Inductance & $0.0092 \Omega / 0.1686 \mathrm{H}$ \\
\hline Rotor resistance / inductance & $0.0121 \Omega$ / $0.1446 \mathrm{H}$ \\
\hline Mutual inductance & $5.6863 \mathrm{H}$ \\
\hline Moment & 0.555 \\
\hline Number of pole pairs & 2 \\
\hline Shunt capacitor & $150 \mathrm{e}-03 \mathrm{KVA}$ \\
\hline Slip & $0.01273+\mathrm{J} 0.293$ \\
\hline $\begin{array}{l}\text { Transmission } \\
\text { parameters }\end{array}$ & $1.936 \Omega / 9.68 \Omega$ \\
\hline Grid resistance/ reactance & \\
\hline
\end{tabular}

